\title{
A PROCISSÃO DO FOGARÉU NA CIDADE DE GOIÁS - IDENTIDADE, CULTURA E TERRITÓRIO: O TURISMO E AS NOVAS TENDÊNCIAS*
}

\author{
THE PROCESSION OF FOGARÉU IN CIDADE DE GOIÁS - IDENTITY, CULTURE \\ AND TERRITORY: TOURISM AND NEW TRENDS \\ LA PROCESIÓN DEL FOGARÉU EN LA CIDADE DE GOIÁS - IDENTIDAD, \\ CULTURA Y TERRITORIO: TURISMO Y NUEVAS TENDENCIAS \\ Luana Nunes Martins de Lima - Universidade Federal de Goiás - Goiânia - Goiás - Brasil \\ luanunes_7@hotmail.com
}

\section{Resumo}

0 objetivo deste artigo é analisar a dinâmica socioespacial instalada na Cidade de Goiás por meio da festa religiosa da Procissão do Fogaréu. Há uma breve discussão sobre a contribuição da festa na construção da identidade local e na formação de um sentimento de pertencimento que estabelece a existência de território. Também analisam-se as transformações e persistências nas práticas socioespaciais dos sujeitos, enfocando a "reinvenção" da festa, sua espetacularização e mercadificação, que opõem-se à verdadeira valoração e representatividade dos signos e símbolos que compõem a cultura da cidade.

Palavras-chave: Procissão do Fogaréu, identidade, cultura, território, turismo.

\section{Abstract}

The objective of this article is to analyze the socio spatial dynamic installed in the Cidade de Goiás through religious party of the Procession of Fogaréu. It presents a brief discussion about the contribution of the party in the construction of local identity and in the formation of a sense of belonging which establishes the existence of territory. It also problematizes the changes and the persistence in the socio spatial practices of the citizens, focusing the "reinvention" of the party, its transformation in spectacle and merchandise, which are opposed to the true value and representation of their signs and symbols that make up the city's culture. Key words: Procession of Fogaréu, identity, culture, territory, tourism.

\section{Resumen}

El objetivo de este artículo es analizar la dinámica socio-espacial instalada en la Cidade de Goiás, a través de la fiesta religiosa de la Procesión del Fogaréu. Presenta una breve discusión sobre la contribución de la fiesta en la construcción de la identidad local y en la formación de un sentimiento de pertenencia que establece la existencia del territorio. También problematiza las transformaciones y persistencias en las prácticas socio-espaciales de los sujetos, centrándose en la "reinvención"de la fiesta, su espectacularización y mercantilización, que se oponen a la valoración real y la representación de sus signos y símbolos que componen la cultura de la ciudad.

Palabras clave: Procesión del Fogaréu, identidade, cultura, território, turismo.

\section{Introdução}

Em várias cidades brasileiras, as manifestações culturais têm ocupado um lugar relevante no que tange à valorização da cultura local, pois

\footnotetext{
* Pesquisa vinculada a projeto financiado pela CAPES, edital Pró-cultura/2009.
} 
apresentam características materiais e simbólicas que representam de alguma forma a sua própria identidade, além de legarem uma singularidade ao território. Por essa razão, entre outras, essa temática tem sido apropriada pela Geografia como objeto de estudo, na perspectiva de pensar o território a partir das práticas socioespaciais.

Para Castells (2000 apud Andrade, 2008, p. 23), a construção de identidades forma-se a partir do que é fornecido pela história, geografia, biologia, pelas instituições produtivas e reprodutivas, pela memória coletiva e por fantasias pessoais, pelos aparatos de poder e pelas revelações religiosas. Entretanto, o autor ainda afirma que "todos esses materiais são processados pelos indivíduos, grupos sociais e sociedades, que reorganizam seu significado em função de tendências sociais e projetos culturais enraizados em sua estrutura social, bem como em sua ótica de tempo/ espaço".

Claval (2008, p. 17), tratando sobre a abordagem cultural na geografia, afirma que o estudo da territorialidade se desenvolve especialmente nas sociedades mais tradicionais "porque as ligações entre os grupos humanos e o espaço onde eles moram são mais diretas e mais fortes". Na medida em que as sociedades se modernizam, as formas de territorialidade, embora não desapareçam, tendem a sofrer mudanças, como demonstrado em estudos mais recentes. Isso ocorre também com a turistificação de lugares, como será demonstrado mais adiante.

Almeida (2008, p. 58-59) considera o território, antes de tudo, como "uma convivialidade, uma espécie de relação social, política e simbólica que liga o homem à sua terra e, simultaneamente, estabelece sua identidade cultural”. E na relação da identidade social com o território situa-se a territorialidade que, para a autora, remete tanto às questões de ordem simbólico-cultural como também ao sentimento de pertencimento a um determinado território. Nesse sentido, "a cultura, como dimensão de operações simbólicas, adere às paisagens e as constrói, conformando-as mediante vivências e significações".

Pretende-se, neste artigo, conduzir a uma reflexão sobre qual tem sido o papel da festa nesse processo de afirmação da identidade local e como, no atual momento de reprodução do capital, essa identidade local é capturada pela lógica do valor de troca, agregando valor a práticas culturais, tornando-as matéria-prima para a indústria do turismo e do lazer e interferindo direta ou indiretamente no modo de vida da comunidade em questão. Bezerra (2007a, p. 4) faz a seguinte consideração: 
A festa, neste contexto das representações, assume um papel importante, pois seu caráter tanto material quanto simbólico contribui para que ela assuma a função de produtora de uma identidade da cidade.” [...]

Neste cenário das imagens e das representações sobre a cidade, a festa tem ganhado uma centralidade, pois seu poder de impressionar, seu caráter estético e ao mesmo tempo simbólico, tem contribuído para que ela assuma o papel de representação da identidade local.

A cultura popular trilhou um lento caminho entre as reflexões e pesquisas realizadas no estado de Goiás ao longo da primeira metade do século XX, mas segundo Silva (2005), já na década de 1940 esses estudos demonstravam o empenho de pensar e definir a cultura regional a partir de vários elementos da cultura popular em um tempo marcado pelo debate de uma identidade nacional. Em Goiás, as festas, as danças, o cancioneiro popular, a religiosidade, entre muitos outros elementos, tornaram-se temas de diversos projetos e trabalhos acadêmicos, livros e através da criação do Instituto Goiano do Folclore em 1967, que teve seu auge entre os anos de 1970 e 1980.

Importante elemento na construção de identidades e de tradições manifestas em práticas culturais, as festas goianas são um misto de fé, cultura popular, e como em todas as festas, um embate entre as dimensões do sagrado e do profano.

Neste artigo, será apresentado o universo cultural da Cidade de Goiás, representado por uma das mais belas e difundidas manifestações culturais e religiosas locais, na qual evidencia-se a participação da comunidade na construção da memória identitária da cidade ao preservar e cultivar até os dias de hoje suas tradições como um princípio de vida.

\section{A Procissão do Fogaréu na Cidade de Goiás}

De acordo com Silva (2001), a Cidade de Goiás, Patrimônio Histórico da Humanidade desde 27 de junho de 2001, título conferido pela Organização das Nações Unidas para a Educação, a Ciência e a Cultura (Unesco), conserva mais de $80 \%$ de sua arquitetura barroco-colonial original, localizando-se em um belo cenário topográfico e atraindo milhares de turistas todos os anos, em virtude de seus museus, casarios, palácios, becos, suas igrejas e ruas, além de, em seu entorno, situar-se a Serra Dourada e 
grandes áreas preservadas do cerrado. A cidade é conhecida também por sua festividade religiosa e pela criação, no final dos anos 1990, do Festival Internacional de Cinema e Vídeo Ambiental (FICA).

Nesse cenário, apresenta-se a festa religiosa da Procissão do Fogaréu, a qual, segundos dados do portal da Cidade de Goiás, foi introduzida na antiga capital pelo padre espanhol João Perestelo de Vanconcelos Espíndola, por volta de 1745 .

A Semana Santa da Cidade de Goiás é uma das mais exuberantes e tradicionais festas religiosas do Brasil. A festa começa à meia noite da quarta-feira da Semana Santa, de acordo com o calendário católico, quando as encenações sobre a Paixão de Cristo movimentam a comunidade, que acompanha o ritual com devoção e curiosidade. Pelas ruas da cidade, é feita a encenação das principais passagens bíblicas que antecedem a crucificação de Cristo.

De acordo com as informações disponibilizadas no portal da Cidade de Goiás, ${ }^{1}$ a Procissão do Fogaréu inicia-se com uma representação do caminho que os romanos percorreram na "caça inquisitorial” a Cristo. Quarenta homens encapuzados com indumentárias coloridas, denominados "farricocos" (antigamente eram doze, passando para vinte), que seriam mantenedores da ordem, carregam tochas acesas entre as ruas escuras da cidade ao som dos tambores da fanfarra. Habitualmente, eles partem da Igreja da Boa Morte e andam descalços pelas velhas ruas da antiga Vila Boa. Fazem sua primeira parada na porta da Igreja Nossa Senhora do Rosário, diante dos "restos da última ceia". Neste momento, o rufar dos tambores diminui, sendo realizada a primeira pregação (homilia) religiosa. Em seguida, os perseguidores seguem para a Igreja de São Francisco de Paula, que representa o Monte das Oliveiras. Um dos farricocos, portando um estandarte de linho pintado em duas faces (obra do artista plástico Veiga Valle, atualmente substituído por outro, obra de Maria Veiga) que simboliza Jesus Cristo, anuncia a prisão do Salvador ao som de um clarinete executado por outro farricoco, quando então é feita a última pregação (homilia), único ato litúrgico realizado pelo Bispo Diocesano, no pátio da Igreja de São Francisco de Paula, contando a prisão de Jesus. Logo após a pregação, o povo acompanha os farricocos de volta à Igreja da Boa Morte, onde se encerra a procissão.

Durante a procissão, a companhia de energia suspende a iluminação pública. O seu percurso pelas ruas é iluminado por quarenta tochas 
levadas pelos farricocos e por outros archotes distribuídos entre o público que o acompanha.

Por muitos anos, o Coral Solo, criado na década de 1970 pelos irmãos Curado e considerado o principal conjunto vocal da cidade, entoa motetos em latim durante a procissão. São cantadas três peças dos Motetos dos Passos, no início (Exeamus), na parada do Rosário (Domine) e após a prisão de Cristo (Pater). A fanfarra constituída de tambores tocando marchas rápidas foi introduzida por volta de 1965, com fim de se fazer silêncio.

A figura dos farricocos retoma as cerimônias espanholas litúrgicas e paralitúrgicas da Semana Santa, como as de Toledo e Sevilha, e ao período da Inquisição. Os trajes são de origem medieval, os quais eram comumente utilizados por penitentes, que podiam, dessa forma, expiar seus pecados sem terem que revelar publicamente sua identidade. Originalmente, nesta cerimônia, só os homens tinham permissão para participar.

A Procissão do Fogaréu é repleta de detalhes e os elementos nela presentes, como a escuridão, as tochas acesas, os homens encapuzados, entre outros, criam um clima medieval assustador e excitante de grande beleza plástica, em que a superstição também está presente. Existem crenças populares de que o demônio estaria solto pelas ruas da cidade nesta noite, aterrorizando todos e, em especial, as crianças que iam para a cama mais cedo. Há também outras crendices relacionadas à presença de personagens do folclore brasileiro, como lobisomem e mula-sem-cabeça, sobretudo na zona rural.

Ainda segundo os dados disponíveis no site oficial da cidade, a procissão dura cerca de uma hora e meia e é acompanhada por cerca de 10 a 15 mil pessoas todos os anos, conforme a média divulgada pela Polícia Militar (PM). A preparação da festa começa um dia antes, com o reconhecimento do trecho a ser percorrido pelos integrantes, marcando o lugar de cada um no trajeto e nas paradas. No dia da procissão, às 15 horas, é realizado o preparo das tochas e, às 19 horas, o último ensaio antes do início da Procissão.

De acordo com a programação divulgada em jornais e meios digitais, os eventos que se seguem após a Procissão do Fogaréu, na quinta e na sexta-feira da Semana Santa são, respectivamente, a representação do Lava-pés e a Paixão de Cristo. Na Quinta-Feira Santa, é celebrada a missa do Lava-pés e a Santa Ceia na Catedral, na Igreja Nossa Senhora do Rosá- 
rio e na Igreja Santa Rita. Na Sexta-Feira Santa, as atividades começam às 6 horas, com a realização da Via Sacra, da Catedral ao Morro do Cruzeiro e, às 15 horas, a comemoração da Cruz na Catedral. Na sexta-feira à noite, são realizados o Canto do Perdão, na Igreja São Francisco de Paula e o Descendimento da Cruz, na Praça do Chafariz. O Sábado Santo é marcado por silêncio, retiro e orações, com penitência comunitária e individual, às 19 horas, na Catedral. No Domingo de Páscoa, as atividades se encerram com missas de manhã e à noite.

Outro exemplo de festividade que remonta a encenação da Paixão de Cristo na Sexta-Feira Santa, pertinente mencionar por sua contextualização, é realizado há onze anos pela comunidade de Quixabá, em Aracati, no litoral leste do Ceará, a 150 quilômetros de Fortaleza. A dramatização começa às 16 horas e reúne cerca de 300 atores, com elenco formado especialmente por moradores da localidade. Todo ano a peça religiosa atrai um público médio de $7 \mathrm{mil}$ pessoas, entre moradores da região, turistas estrangeiros e de vários estados do Brasil.

Além de uma expressão de religiosidade e da cultura popular brasileira, as encenações da Semana Santa representam uma atração turística. Há muitos anos essas festas tradicionais atraem milhares de turistas do Brasil e do exterior. Em Goiás e no Ceará, o Serviço Brasileiro de Apoio às Micro e Pequenas Empresas (SEBRAE) apoia espetáculos que fazem parte dessa tradição cristã. Já consta, na Cidade de Goiás, a existência de políticas públicas da administração local, bem como instituições de ensino e órgãos que trabalham na divulgação e publicização da Procissão do Fogaréu. Vale ressaltar que o Grupo Focal é formado por representantes da comunidade que apoiam a sua realização e a Organização Vilaboense de Arte e Tradição (OVAT) é a executora da festa religiosa.

Resistência às tendências globais: reinvenção, espetacularização e mercadificação

As manifestações culturais presentes na Cidade de Goiás apresentam uma conexão com o contexto sociocultural de seu entorno: a região do cerrado. Os aspectos dessa conexão podem ser extraídos na história de Goiás, nas formas de vida, de produção e nos rituais culturais e religiosos vivenciados pela comunidade local.

O estudo dessas manifestações culturais, apropriado mais recentemente pela Geografia, consiste não apenas em uma perspectiva exterior, 
ou na simples apreensão das práticas socioespaciais dos sujeitos e como vem se dando sua transformação mediante a globalização, mas também se concentra nos aspectos de religiosidade e fé absorvidos nessas práticas. Sobre isso, Claval (2008, p. 21) argumenta que

a vivência religiosa não se resume ao sentido do sagrado. Ela também integra o recolhimento, a meditação, a oração, a comunhão através do canto ou da dança, o êxtase. Cada categoria de experiência religiosa é ligada a momentos e lugares específicos. Deste modo, os geógrafos penetram na vida religiosa; a estudam do interior. Eles percebem o sofrimento dos fiéis e sua esperança de um futuro melhor - nesse mundo, ou no outro mundo.

Alguns elementos importantes podem ser identificados a fim de compreendermos a dinâmica instalada na cidade por meio da Procissão do Fogaréu: a dimensão territorial e cultural da Procissão do Fogaréu e sua correlação com as paisagens em que ocorre e com o contexto social, levando-se em conta aspectos da própria geografia local; as políticas culturais e o papel de órgãos e organizações na representação da cultura na cidade; a atuação local da mídia; e, sobretudo, o desenvolvimento do turismo, que se estabelece como principal atividade econômica na cidade.

Sabe-se que o turismo surgiu na Cidade de Goiás como uma proposta econômica de inclusão social, contribuindo para novas perspectivas de valorização da vida, para o usufruto de produtos culturais e para uma melhor distribuição de renda. Contudo, ele está associado a uma economia de mercado que exclui parcelas significativas da população de participarem do crescimento econômico e social; além disso, transforma as manifestações culturais, as práticas de fé, crenças, saberes e outros elementos da cultura popular em mero espetáculo a ser visto, filmado e levado como memorial de um lugar exótico visitado.

O turismo deve ser analisado como um fenômeno econômico-cultural moderno dinamizado por uma sociedade de consumo e, portanto, essa análise deve se estender para além da dimensão material do espaço. Sua produção, reprodução, fragmentação e homogeneização no/do espaço através das novas espacialidades da vida social, material e simbólica, por vezes produzem lugares turísticos subordinados aos atores hegemônicos, gerando uma desordem desmedida na estrutura social.

Meneses (2004, p. 13) afirma que é possível "pensar em um planejamento diferente, em uma percepção mais acurada, em que o bem 
histórico-cultural possa ter tratamento de construção histórica dinâmica e em andamento e possa propiciar inclusão identitária e social de quem participa ativamente dessa dinâmica”.

Novas formas de ação na gestão de bens culturais surgem todos os dias na tentativa de se articular o patrimônio cultural, material ou imaterial, ao turismo. Infelizmente, nem todas essas ações favorecem a inclusão da comunidade local, que preservou e guardou o bem histórico, gerando novas perspectivas de melhoria da qualidade de vida a partir da utilização responsável desse bem patrimonial.

Em uma abordagem sobre a disputa do território do Cerrado, Chaveiro (2008b, p. 85-86) sintetiza como alguns atores que participam dessa disputa transformam a cultura do cerrado e sua potencialidade em negócio para lazer e turismo, adequando a cultura local à demanda por consumo. Vejamos:

As festas, as temporadas e eventos criados, dessa maneira, se ajustam à criação de um desejo baseado na performance, no narcisismo, na corpolatria, na autoajuda, na institucionalidade religiosa e outros. [...] Convém averiguar o sentido crítico ao modo de produção e o respeito pelas comunidades tradicionais e aos seus saberes e modos de vida. A ideia de pertencimento se apresenta como fonte política de defesa do patrimônio integrado do cerrado. [...] Os ritos do cerrado, suas festas, seu folclore, os hábitos alimentares, as narrativas orais, sua literatura, se tornam ingredientes de formas de adesões das lutas contra a expropriação do cerrado e de seus sujeitos.

Ainda sobre essa atuação mercadológica, Santos (2008, p. 130) afirma que "a identidade pode ser evocada como tradição" e "na perspectiva histórica, ela pode se manifestar enraizada no lugar, sendo entendida como pertencimento, e no conjunto pode ser uma reação às forças do mercado, mas pode ser também uma resposta a elas”. Baseando-se nessa afirmação, há também a necessidade de se considerar a festa como é vista e sentida pela própria comunidade local, ou seja, sua percepção sobre a forma de conexão da festa com a história e com a construção identitária da cidade, e que tipos de impactos ou contribuições o turismo expressa para essa comunidade.

Faz-se necessário também uma investigação do papel que a mídia desempenha com relação à festa em questão. Para Bezerra (2007b, p. 70), é preciso "situar esses entrelaçamentos entre festa, cidade e identidade 
nesse momento histórico da dinâmica capitalista em que o uso da imagem tem assumido uma centralidade, resultando assim no processo de espetacularização da sociedade”. Ainda segundo a autora,

esse processo de espetacularização se situa nesse momento histórico da dinâmica capitalista em que o uso da imagem e a intensificação do consumo assumem uma centralidade, estando intrinsecamente relacionados, pois a aceleração do tempo de giro na produção da volatidade envolve a manipulação do gosto e da opinião. É a partir desse quadro [...] que a publicidade e as imagens da mídia passaram a ter um papel mais integrador nas práticas culturais, tendo assumido agora uma importância muito maior na dinâmica de crescimento do capitalismo.

Almeida (2004) trata do contraste entre desenvolvimento turístico e desenvolvimento local, enfatizando que a construção do espaço turístico se dá com a desconstrução do lugar. Assim, as transformações do ambiente e das relações sociais, bem como do patrimônio cultural que antes permitiram a existência desse lugar são em "função do outro", para a conservação do atrativo e não para a valoração local, sendo esses elementos desterritorializados para serem exclusivamente revalorizados pelo turista.

A autora ainda afirma que o lugar deve corresponder às imagens e ao imaginário daquele que é turista, o que supõe um desvio do uso tradicional do lugar. "É o olhar extasiado, do "outro", do forasteiro, admirando paisagens que atribuem valor, [...] parte de seu próprio conjunto de valores e que, associado aos interesses do lucro, pela mídia, postais e guias de viagens, inventam o lugar turístico" (Almeida, 2008, p. 125).

É possível observar a supervalorização da Procissão do Fogaréu como espetáculo "chave” da Cidade de Goiás. Entretanto, não há igualmente o reconhecimento de uma cultura popular, afinal, as pessoas que assistem às encenações, representações e missas desconhecem, em grande parte, a história de vida dos moradores, a história da festa como prática da cultura vilaboense, não compreendem o sentido dos rituais e os valores, consumindo apenas as imagens.

Além disso, a espetacularização que permeia a festa gera uma grande preocupação com a imagem e requer esforços cada vez maiores dos participantes e da comunidade em geral para atender um público exigente.

Tanto a cultura turística como a cultura original da população local se metamorfoseiam durante o encontro entre elas: o turista, no desejo de realizar suas expectativas e fantasias de uma cultura turística, e as popu- 
lações locais, que reduzem sua visibilidade, uma vez que o destaque são seus atrativos turísticos e suas representações. Por isso mesmo, mantêm esses atrativos e representações e não medem esforços para que sejam apreciados nos seus aspectos de estética, distinção e singularidade.

Ao longo dos anos, a mercadificação das manifestações culturais na cidade tendem sempre a transformá-las gradativamente, seja aumentando componentes, seja incorporando novos elementos aos rituais, ou ainda modificando vestimentas, instrumentos etc. Carneiro (2010) chega a afirmar que a Procissão do Fogaréu foi reinventada pela OVAT, sob novos moldes, para atender a essa demanda turística. A autora cita que um dos principais fundadores da organização, Elder Camargo dos Passos, registrou em uma de suas obras o papel da OVAT como uma organização que valoriza as tradições em razão do turismo e da renda que gera.

Para os devotos e para aqueles que participam da festa religiosa, contudo, a fé cristã e suas crenças são os motivos de sua realização. E talvez sejam os principais elementos responsáveis pela continuidade da procissão como prática sociocultural na cidade.

\section{Considerações finais}

Com a potencialização turística dos polos históricos, aspectos de grande relevância da própria cultura, bem como seus significados e simbolismos têm sido ignorados ou espetacularizados. Enquanto isso, a comunidade local permanece, muitas vezes, à margem do desenvolvimento advindo do turismo.

O mau uso e a apropriação indevida dos elementos simbólicos e identitários das populações receptoras constituem uma tentativa de gerar produtos comercializáveis que ressignificam a própria realidade vivida pelos atores sociais envolvidos, criando um novo valor, um novo olhar, tanto das populações locais sobre si mesmas como dos turistas sobre a cultura alheia. O legado cultural, assim transformado em produto para o consumo, perde seu significado autêntico. A cultura deixa de ser importante por si mesma e passa a ser importante por suas implicações econômicas.

Nessa lógica, as inovações, os eventos culturais e os espetáculos são latentes, muitas vezes resgatados ou recriados, tornando-se o "cartão postal”, o principal convite à visita. A mídia promove o encontro entre a cultura e a mercadoria, construindo imaginários numa difusão de imagens 
superficiais que tentam reproduzir o real num processo mercantilizador das singularidades culturais.

Na lógica do turismo, é aceitável e até necessário impor alguns atrativos, recriar ou transformar algo em espetáculo, fazer modificações no que é original para agregar valor, atribuir um sentido exótico ou que cause maior interesse. No entanto, essas ações resultam no estabelecimento de uma nova estrutura socioespacial e atribuem novos valores aos símbolos identitários que apresentam um sentido diferenciado na memória coletiva local.

Com a turistificação, o lugar assume novas formas e funções, afetando essencialmente as dimensões materiais e simbólicas da sociedade.

Apesar das tendências globais que exercem influência nas dinâmicas locais, as festas ainda manifestam resistência ao processo de globalização que procura homogeneizar todas as práticas socioculturais. Para Costa (2008, p. 70),

festar ainda é, mesmo que em processo de cooptação, a realização da vida e de toda uma dimensão da reprodução social que ainda carece de estudos em busca de outras possibilidades, da realização de práticas libertárias e mais justas, de uma cidade para todos. $\mathrm{Na}$ contramão desse pensamento, o capital apropria-se do espaçotempo das cidades impondo a lógica da fluidez, do movimento, da efemeridade, da imagem, dos simulacros. Mas a dimensão da riqueza da vida cotidiana persiste, assim como nas práticas festivas $[\ldots]$.

Entende-se que a recuperação da memória coletiva, mesmo que seja para reproduzir a cultura local para os turistas, produz o desejo de afirmação da própria identidade e, num ciclo de realimentação, estimula uma procura por recuperar cada vez mais seu próprio passado. Além disso, leva a comunidade ao conhecimento de seu patrimônio, o que conduz à valorização.

O turismo, com base na valorização e preservação da cultura, e não na sua exploração comercial, permite que a comunidade se engaje no processo de recuperação da memória coletiva, de reconstrução da história e de verificação das fontes, fortalecendo os seus sentidos e a sua conexão com o espaço vivido, sua identidade cultural.

A partir da apreensão e problematização da festa religiosa da Procissão do Fogaréu, é possível identificar a representatividade dos signos e símbolos que compõem a cultura do lugar, favorecendo a abertura de no- 
vas consciências de vida que se contraponham às vertentes economicistas do turismo e reafirmem, nas palavras de Chaveiro (2008a, p. 135), “a vida como patrimônio e a cultura como elemento central da vida humana”.

\section{Nota}

1. http://www.vilaboadegoias.com.br

\section{Referências}

ALMEIDA, Maria Geralda de. Desenvolvimento turístico ou desenvolvimento local? Algumas reflexões. In: ENTBL - Planejamento para o desenvolvimento local. Curitiba. Anais... Curitiba, 2004.

ALMEIDA, Maria Geralda de. Diversidades paisagísticas e identidades territoriais e culturais do Brasil sertanejo. In: ALMEIDA, M. G.; CHAVEIRO E. F.; BRAGA, H. C. (Orgs.). Geografia e cultura: os lugares da vida e a vida dos lugares. Goiânia: Vieira, 2008. p. 47-74.

ANDRADE, Rodrigo Borges de. Práticas socioculturais e religiosas: elementos constituintes do lugar. In: ALMEIDA, M. G.; CHAVEIRO, E. F.; BRAGA, H. C. (Orgs.). Geografia e cultura: a vida dos lugares e os lugares da vida. Goiânia: Vieira, 2008. p. 22-46.

BEZERRA, Amélia C. A. Cidade, Cultura e Planejamento em Tempo de Espetáculo. In: ENCONTRO NACIONAL DA ANPEGE, 7, 2007, Niterói. Anais... Niterói, 2007a. 1 CD-ROM.

BEZERRA, Amélia C. A. Festa e identidade: a busca da diferença para o mercado de cidades. In: ARAÚJO, F. G. B.; HAESBAERT, R. (Orgs.). Identidades e territórios: questões e olhares contemporâneos. 1. ed. Rio de Janeiro: Access, 2007b. p. 69-92.

CARNEIRO, Keley Cristina. A bola da vez. Estudo de caso: uma questão de patrimônio - O turismo e a Cidade de Goiás. Revista Saber Eletrônico, ano 1, v. 2. Jussara: Unifaj, 2010. Disponível em: <http://www.unifaj.edu.br/NetManager/ documentos/ A\%20Bola\% 20da\%20Vez.pdf>. Acesso em: 16 dez. 2010.

CHAVEIRO, Eguimar Felício. A cultura como patrimônio e a vida como cultura: disputas de sentidos na Cidade de Goiás - um patrimônio da humanidade. Revista OLAM, Ciência e Tecnologia, ano 8, v. 8, n. 1. Rio Claro, p. 122-136, 2008a. Disponível em: <http://www.periodicos.rc.biblioteca.unesp.br/index.php/olam/ article/ viewArticle/1238>. Acesso em: 16 dez 2010.

CHAVEIRO, Eguimar Felício. O cerrado em disputa: sentidos culturais e práticas sociais contemporâneas. In: ALMEIDA, M. G.; CHAVEIRO E. F.; BRAGA, H. C. (Orgs.). Geografia e cultura: os lugares da vida e a vida dos lugares. Goiânia: Vieira, 2008b. p. 75-97. 
CLAVAL, Paul. Uma, ou algumas, abordagem (ns) cultural (is) na geografia humana. In: SERPA, Ângelo (Org.). Espaços culturais: vivências, imaginações e representações. Salvador: EDUFBA, 2008. p. 15-29.

COSTA, Carmem Lúcia. As festas e o processo de modernização do território goiano. R. $R A^{\prime} E G A$ n. 16. Curitiba: Ed. da UFPR, 2008. Disponível em: <http://ojs. c3sl.ufpr.br/ojs-2.2.4/index.php/raega/article/view/12679/9917>. Acesso em: 16 dez. 2010.

MENESES, José Newton Coelho. História e turismo cultural. Belo Horizonte: Autêntica, 2004.

PORTAL DA CIDADE DE GOIÁS. Disponível em: < http://www.vilaboadegoias. com.br> Acesso em: 18 nov. 2009.

SANTOS, Rosselvelt José. (Re) Ocupação do cerrado: novas gentes, outras identidades. In: ALMEIDA, M. G.; CHAVEIRO E. F.; BRAGA, H. C. (Orgs.). Geografia e cultura: os lugares da vida e a vida dos lugares. Goiânia: Vieira, 2008. p. 98-136.

SILVA, Antônio Moreira da. Dossiê de Goiás - Enciclopédia Regional: um compêndio de informações sobre Goiás, sua história e sua gente. Goiânia: Master Publicidade, 2001.

SILVA, Mônica Martins da. Identidades, culturas, representações festivas e a invenção do folclore em Goiás (1940-1980). Revista Guanicuns, n. 2, p. 195-210. Faculdade de Anicuns: 2005. Disponível em: <http://www.faculdadeanicuns.edu. br/revista/rguanicuns02/pdfs/l_nr2_artigo09_pgs_195_210.pdf $>$. Acesso em: 18 nov. 20.

Luana Nunes Martins de Lima - Graduada em Turismo pelo Instituto Federal de Educação, Ciência e Tecnologia de Goiás. Especialista em História Cultural pela Universidade Federal de Goiás. Mestranda em Geografia pela Universidade Federal de Goiás. 